1 Nestel PJ, Billington T. Effects of probucol on low density lipoprotein removal and high density lipoprotein synthesis. Atherosclerosis 1981; 38: 203-9.

2 McPherson R, Hogue M, Milne RW, Tall AR, Marcel YL Increase in plasma cholesteryl ester transfer protein during Increase in plasma cholesteryl ester transfer protein during

3 Miettinen TA, Huttunen JW, Kuusi T, et al. Effect of probucol on the activity of postheparin plasma liport probucol on the activity of postheparin plasma lipoprotein lipase and hepatic lipase. Clin Chim Acta 1981; 113: 59-64. Lock DR, Kuisk I, Gonen B, Patsch W, Schonfeld G. Effect of probucol on the composition of lipoproteins and on VLDL

5 Vessby E, Lithell H, Hellsing K, et al. Efiects of bezafibrate Vessby E, Lithell $\mathrm{H}$, Hellsing $\mathrm{K}$, et al. Efiects of bezafibrate
on the serum lipoprotein lipid and apolipoprotein composition, lipoprotein triglyceride removal capacity and the fatty acid composition of the plasma lipid esters. Atherosclerosis 1980; 37: 257-69.
6 Mordasini R, Riesen W, Oster P, Keller M, Middelhoff G, Lang PD. Reduced LDL- and increased HDL-apoprotein in patients with hypercholesterolaemia under treatment with bezafibrate. Atherosclerosis 1981; 40: 153-8.

7 Micheli M, Pometta D, Gustafsson A. Treatment of hyperlipoproteinemia type IIA with a new phenoxy-isobutyric acid derivative, procetofen. Int $f$ Clin Pharmacol Biopharm $1979 ; 17: 503-6$.

8 Lehtonen A, Viikari J. Fenofibrate and cholestyramine in type II hyperlipoproteinemia. Artery 1982; 10: 353-67.

\title{
Polymyalgia rheumatica, temporal arteritis and malignancy
}

\author{
CA Speed, I Haslock
}

\begin{abstract}
Summary
The use of steroid therapy in polymyalgia rheumatica and temporal arteritis is necessary and usually effective, but may mask coexisting disease. The importance of early consideration of other disorders in such patients is illustrated by three case histories.
\end{abstract}

Keywords: polymyalgia rheumatica, temporal arteritis, malignancy, Waldenstrom's macroglobulinaemia

Polymyalgia rheumatica (PMR) and temporal arteritis (TA) are disorders which are usually steroid responsive and easily monitored by the clinical picture and acute phase parameters such as the erythrocyte sedimentation rate (ESR). The clinical features are often nonspecific and steroid therapy may mask features of coexisting diseases. We describe three cases of PMR/TA, in which an apparent flare of the disease was in fact an initial presentation of another disease - in two cases, a malignancy. The importance of maintaining a high degree of clinical suspicion in the management of such patients is emphasised and the association of $\mathrm{PMR} / \mathrm{TA}$ with other disorders is discussed.

\section{Case histories}

Case 1

A 60-year-old male smoker presented with a two-month history of bilateral temporal headaches. Examination revealed pulsatile, thickened temporal arteries. An ESR was $97 \mathrm{~mm} / \mathrm{h}$; a temporal artery biopsy confirmed cranial arteritis. A chest X-ray performed at the time was consistent with chronic obstructive airways disease, with no focal lesions. His symptoms and ESR responded dramatically to oral steroids.

Eighteen months later, he was re-referred by his general practitioner with letheragy and an ESR of $84 \mathrm{~mm} / \mathrm{h}$. This had failed to respond to increasing his steroids from 5 to $40 \mathrm{mg}$ daily. A right supraclavicular lymph node was palpable. A chest X-ray revealed an enlarged right hilum and right lower lobe collapse. A lymph node biopsy confirmed adenocarcinoma.

Case 2

A 60-year-old male smoker presented to his general practitioner with a seven-month history of temporal headaches, scalp tenderness and proximal myalgia. An ESR was $116 \mathrm{~mm} / \mathrm{h}$. A diagnosis of temporal arteritis was made and he responded dramatically to steroids. One month later, whilst on $40 \mathrm{mg}$ prednisolone daily, he returned to his doctor complaining of lethargy. An ESR was $107 \mathrm{~mm} / \mathrm{h}$. He failed to respond to increasing his steroid dosage and was referred to the rheumatology clinic. A chest X-ray was performed and revealed consolidation and collapse of the right lower and middle lobes. B:onchoscopy confirmed squamous cell carcinoma.

\section{Case 3}

A 53-year-old woman presented to her general practitioner with a two-month history of proximal muscle stiffness and non-specific head- N aches. Examination was unremarkable; an ESR श्? was $65 \mathrm{~mm} / \mathrm{h}$. A diagnosis of polymyalgia rheumatica was made. Her symptoms responded to prednisolone ( $30 \mathrm{mg} /$ day) within two days. However, her ESR remained elevated, varying between 45 and $62 \mathrm{~mm} / \mathrm{h}$, so she was referred for a specialist opinion. Further investigations revealed an IgM kappa paraproteinaemia; urinary Bence Jones proteins were absent. Her plasma viscosity was $1.89 \mathrm{cp}$; full blood count and C-reactive protein were normal, apart from a mild neutrophilia. A bone marrow biopsy was consistent with a diagnosis of Waldenstrom's macro-
Department of Cleveland Hospital, Middlesbrough Cleveland TS4 3BW, CA Speed

I Haslock 


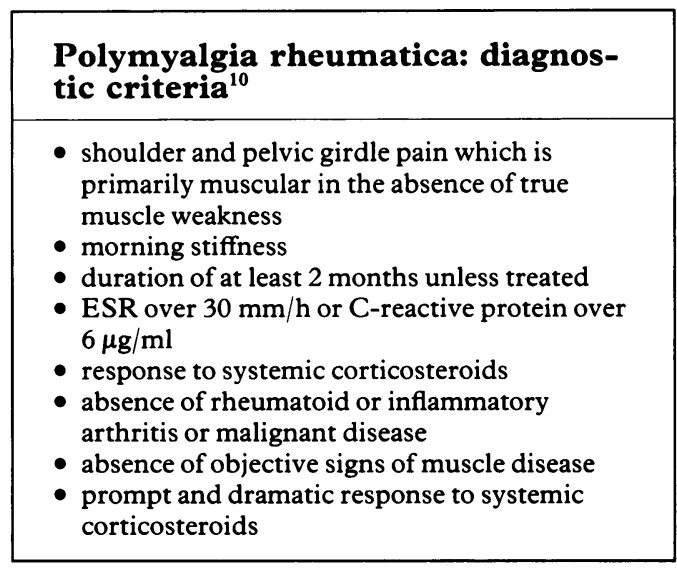

globulinaemia. As her C-reactive protein was normal when she was asymptomatic, this was used to monitor the activity of her PMR thereafter.

\section{Discussion}

Polymyalgia rheumatica and temporal arteritis are two closely related syndromes with overlapping clinical features. ${ }^{1}$ Whether they are different manifestations of the same disease remains controversial. ${ }^{2,3}$

The above case histories illustrate several important points in the management of PMR/ TA. PMR and TA have been reported as manifestations of underlying malignancy. ${ }^{4,5}$ However, various studies have failed to demonstrate an increased incidence of malignancy in these patients. ${ }^{6-8} \mathrm{~A}$ common view is that any association is coincidental, due to the increased incidence of malignancies and PMR/TA in older age groups. A confusing feature is that a malignancy may present with similar symptoms to PMR/TA due to a paraneoplastic phenomenon. Haga et al found an elevated risk of developing malignancy in patients with biopsy-proven TA. ${ }^{9}$ They noted a long time interval between the two events, making a paraneoplastic mechanism unlikely.

All three cases satisfied the accepted diagnostic criteria for PMR/TA. ${ }^{10,11}$ None of the patients had had a chest X-ray nor serum electrophoresis prior to referral to the rheumatology unit; these must be accepted as part of the routine investigations, in addition to an ESR, plasma viscosity, full blood count, and serum biochemistry. ${ }^{12}$

The acute phase response is reflected in elevated ESR, plasma viscosity and C-reactive protein values; there is a good correlation between the ESR and plasma viscosity ${ }^{13}$ and the ESR and C-reactive protein. ${ }^{14}$ Hickling et al found these three tests to be equally effective in measuring disease activity. ${ }^{15}$ The ESR may remain elevated with high dose steroids in a patient with PMR/TA, in spite of a symptomatic response. ${ }^{12}$ In this situation it is vital to remain alert to other causes of a high ESR. Additional investigations to those outlined above will be guided by the clinical picture; other symptoms may be revealed by a reduction of the steroid dose.
Temporal arteritis: diagnostic criteria $^{10}$

- positive temporal artery biopsy or cranial artery tenderness noted by a physician

- one or more of the following: visual disturbance, headache, jaw pain, cerebrovascular insufficiency

- ESR over $30 \mathrm{~mm} / \mathrm{h}$ or C-reactive protein over $6 \mu \mathrm{g} / \mathrm{ml}$

- response to systemic corticosteroids

\section{PMR/TA: appropriate investiga-} tions

- full blood count

- ESR or plasma viscosity

- serum biochemistry

- serum electrophoresis

- chest X-ray

- consider: temporal artery biopsy, thyroid function tests, creatine kinase, autoantibody screen

\section{Summary points}

- coexisting disease must be considered in all cases of PMR/TA

- appropriate screening investigations are mandatory in all cases of suspected PMR/TA

- corticosteroid therapy in PMR/TA is necessary and usually effective

- further investigations are necessary should the plasma viscosity remain elevated in spite of corticosteroid treatment

The ESR may also be normal in the presence of active disease; ${ }^{16}$ in cases of doubt, measuring more than one acute phase reactant improves diagnostic accuracy. ${ }^{13}$ Case 3 highlights the advantage of using other acute phase parameters in the monitoring of PMR. As the patient's C-reactive protein was normal but the ESR and plasma viscosity elevated at the time of diagnosis of Waldenstrom's macroglobulinaemia (when her polymyalgic symptoms had settled), her PMR was monitored by her Creactive protein and clinical status.

\section{Conclusions}

These cases highlight the need for the clinician to remain alert in the diagnosis and management of PMR/TA. Other causes for an elevated ESR must be considered at all stages. Routine investigations should include a chest $\mathrm{X}$-ray and serum protein electrophoresis. In most cases, the disease should be managed on the basis of the patient's clinical status, not laboratory markers. The true association between PMR/ TA and other diseases such as malignancy remains to be established. 
1 Chakravarty K, Scott DGI. Large vessel vasculitis. In Maddison PJ, Isenberg DA, Woo P, Glass DN, eds. Oxfor textbook of rheumatology, Vol 2. Oxford: Oxford University Press, 1993; pp 873-83.

2 Jones JG. Clinical features of giant cell arteritis. Bailliere's Clin Rheumatol 1991; 5: 3-30.

3 Healey LA. Relation of giant cell arteritis to polymyalgia rheumatica. Bailliere's Clin Rheumatol 1991; 5: 371-8.

4 Hunder G, Disney T, Emmerson L. Polymyalgia rheumatica. Mayo Clin Proc 1969; 44: 849-75.

5 Mackenzie AH, Scherbel AL. Connective tissue syndromes associated with carcinoma. Geriatrics 1963; 18: 745 .

6 von Knorring J, Somer T. Malignancy in association with polymyalgia and temporal arteritis. Scand $\mathcal{f}$ Rheumatol 1974; polymyalgia $129-35$.

7 Huston KA, Hunder GG, Lie JT, Kennedy RH, Elveback LR. Temporal arteritis: a 25-year epidemiological, clinical and pathological study. Ann Intern Med 1978; 88: 162-7.

8 Bengtsson BA, Malmvall BE. Prognosis of giant cell arteritis including temporal arteritis and polymyalgia rheumatica. Acta Med Scand 1981; 209: 337-45.

9 Haga HJ, Eide GE, Brun J, Johansen A, Langmark F. Cancer in association with polymyalgia rheumatica and temporal arteritis. $\mathcal{F}$ Rheumatol 1993; 20: 1335-9.
10 Jones JG, Hazleman BL. The prognosis and management of polymyalgia rheumatica. Ann Rheum Dis 1981; 40: 1-5.

11 Ellis ME, Ralston S. The ESR in the management of the polymyalgia/giant cell arteritis syndrome. Ann Rheum Dis 1983; 42: 168-70.

12 Dasgupta B, Panayi GS. Polymyalgia rheumatica. In: Maddison PJ, Isenberg DA, Woo P, Glass DN, eds. Vol 2 . Oxford: Oxford University Press, 1993; pp 865-73.

13 Britain GPH, McIlwaine GG, Bell JA, Gibson JM. Plasm viscosity or erythrocyte viscosity or erythrocyte sedimentation rate in the diagnosis

14 Parker JR, Jones JG, Hazelman BL. Relationship of the erythrocyte sedimentation rate to acute phase proteins in polymyalgia rheumatica and giant cell arteritis. Ann Rheum Dis 1981; 40: 493-

15 Hickling P, Dixon JS, Bird HA, Young JD, Burton $H$, Wright V. Acute phase reactants as predictors of the success of steroid withdrawal in PMR. Br $\mathcal{F}$ Radiol 1986; 25: 98 (abstract 23).

16 Wong RL, Korn JK. Temporal arteritis without an elevated erythrocyte sedimentation rate. Am f Med 1986; 80: 959-64.

\title{
Dysphagia due to secondary achalasia as an early manifestation of squamous cell carcinoma
}

\author{
HK Makker, R Chisholm, AJ Rate, J Bancewicz, A Bernstein
}

\begin{abstract}
Summary
A 59-year-old man, a smoker, presented with features of airflow obstruction due to squamous cell carcinoma of central airways mimicking chronic obstructive airways disease. He also had pronounced dysphagia. Computed tomographic and magnetic resonance imaging scans showed mediastinal tumour invasion but no direct oesophageal involvement. Oesophageal manometry studies revealed that dysphagia was due to the oesophageal motility disorder, secondary achalasia.
\end{abstract}

Keywords: lung cancer, airflow obstruction, dysphagia, achalasia

Early central airway tumours are frequently missed as their presentation often mimics airflow obstruction due to either chronic obstructive airways disease or asthma. A diagnosis is made when the tumour is advanced and associated with other symptoms such as haemoptysis. Dysphagia is usually a late symptom in patients with lung cancer. It is caused by mechanical obstruction of the oesophagus either by extrinsic compression due to mediastinal lymphadenopathy or direct tumour invasion. We describe a patient with central airway lung cancer in whom dysphagia was an early manifestation of the disease caused by a motility disorder.

\section{Case report}

A previously healthy 59-year-old male smoker presented with a three-month history of dyspnoea on exertion associated with wheeze and nocturnal cough. He also complained of dysphagia for solids of three weeks duration and a weight loss of $4 \mathrm{~kg}$. Examination revealed no clubbing of finger nails or enlargement of cervical lymph nodes. He was not dyspnoeic and examination of respiratory system, cardiovascular system and abdomen revealed no abnormal findings. Chest X-ray was normal except for hyperinflated lung fields. Pulmonary function test showed mild airflow obstruction with PEFR of $415 \mathrm{l} / \mathrm{min}$ and $\mathrm{FEV}_{1} / \mathrm{FVC}^{2.59} /$ 3.671 (predicted $504 \mathrm{l} / \mathrm{min}, 3.24 / 4.031$ ). Other tests of pulmonary function such as flow volume loop studies, lung volumes and transfer factor were normal. Oesophago-gastroscopy and barium swallow examination for dysphagia revealed no obstructive lesion or mucosal abnormality.

Airflow obstruction associated with symptoms of exertional dyspnoea, wheeze and cough was suggestive of either chronic obstructive airways disease or late onset asthma and the patient was treated with inhaled beta- 2 agonis and corticosteroids and oral corticosteroids However there was no improvement in the symptoms and two months later the patient presented with further symptoms of hoarseness of voice and haemoptysis. Fibre-optic bronchoscopy revealed squamous cell carcinoma involving airway mucosa of the lower third of the trachea and proximal part of both major bronchi, and paralysis of the left vocal cord. Airway narrowing due to the tumour was confirmed on computed tomography (CT) and magnetic resonance imaging (MRI) scans of the chest, with a cuff of neoplastic tissue seen around the lower part of the trachea and proximal major airways (figure). There was no evidence of local lymph node enlargement or direct oesophageal involvement but tumour
Hope Hospital, Cardiorespiratory

Department of

R Chisholm

Department of

Surgery

J Bancewicz

Accepted 15 February 1995 